\title{
Especificação de uma Plataforma Aberta para o Ensino de Robótica a Distância
}

\author{
Edviges de Fátima Chaves de Lima ${ }^{1}$, Clauirton de Albuquerque Siebra ${ }^{1}$ \\ ${ }^{1}$ Centro de Informática - UFPB - João Pessoa - PB - Brasil \\ \{edvigeslima, clauirton\}@ci.ufpb.br
}

\begin{abstract}
Robotics as well as other areas of engineering and computing, requires the use of specific laboratories for development of practical activities by students. This becomes a further difficulty in distance teaching, whereas the majority of poles does not have infrastructure to maintain such laboratories. One solution currently employed is the use of virtual laboratories, which apply some kind of robot simulator. This paper extends this approach also allowing students to remotely apply their algorithms in real robots. To that end, the development of a real robot in an open platform and its virtual model are discussed. The system architecture is also specified, focusing on the functionalities provided to students.
\end{abstract}

Resumo. A robótica, assim como outras áreas da engenharia e computação, requer o uso de laboratórios específicos para o desenvolvimento de atividades práticas pelos alunos. Isso se torna uma dificuldade a mais no âmbito do ensino a distância, uma vez que a grande maioria dos polos não possui infraestrutura para manter tais laboratórios. Uma solução atualmente utilizada é o uso de laboratórios virtuais, os quais aplicam algum tipo de simulador de robôs. Este artigo estende tal abordagem permitindo que os alunos também apliquem remotamente seus algoritmos em robôs reais. Para isso, é apresentado o desenvolvimento de um robô real em uma plataforma aberta e do seu modelo virtual. A arquitetura do sistema também é especificada com foco nas funcionalidades providas aos alunos.

\section{Introdução}

Sob o incentivo da popularização da Internet e dos avanços da tecnologia, especificamente da Tecnologia da Informação e da Comunicação (TIC), a educação a distância $(\mathrm{EaD})$ vem evoluindo cada dia mais. Com isso, há uma crescente preocupação em prover o melhor desempenho para esta modalidade de ensino que permite a troca de conhecimento entre indivíduos que podem estar separados temporalmente e/ou geograficamente.

No Brasil, a EaD está sendo adotado na educação pelos mais variados níveis, desde a educação básica, seguido pela educação de jovens e adultos (EJA) até o ensino superior, bem como formação profissional, programas de qualificação, entre outros. Segundo o censo realizado pela ABED (2014) sobre a EaD no Brasil, cerca de 80,3\% das instituições de $\mathrm{EaD}$ analisadas usam ferramentas virtuais nos cursos, tais como mídias de acesso a vídeo, videoconferência, webconferência, animações, laboratórios virtuais/simuladores, jogos educativos, realidade aumentada, objetos de aprendizagem, blogs/microblogs, entre outros. No entanto, $65,4 \%$ não utiliza simuladores/laboratórios didáticos virtuais nos cursos de $\mathrm{EaD}$ alegando dificuldades como custos de aquisição e 
manutenção, pouco ou nenhum domínio técnico, ou mesmo a falta de soluções inovadoras com baixo custo. Apesar disso, a maioria destas instituições concorda que o uso desses recursos tecnológicos contribui para a motivação e o interesse do aluno, assim como para o desenvolvimento de habilidades cognitivas e da criatividade.

Dessa forma, o presente artigo visa apresentar soluções que possam melhorar a experiência prática dos alunos em laboratórios virtuais de robótica inerentes aos cursos a distância voltados para engenharias e computação, os quais são relativamente novos como tema de cursos a distância, mas tem sido os que mais atraem alunos, ainda segundo a ABED (2014). Sendo assim, o restante do artigo está organizado da seguinte forma. A seção 2 apresenta os trabalhos que contribuíram para o desenvolvimento desta pesquisa. A seção 3 descreve as ferramentas e os métodos utilizados na elaboração do projeto. Por fim, a seção 4 discute as considerações finais e os trabalhos futuros.

\section{Trabalhos Relacionados}

Em relação aos laboratórios de $\mathrm{EaD}$, as soluções geralmente empregadas são as ferramentas de simulação devido ao baixo custo de criação e manutenção. No entanto, com o intuito de tornar as atividades práticas dos laboratórios mais realistas, também são utilizados os laboratórios remotos, que são laboratórios físicos que podem ser efetivamente utilizados pelos alunos de qualquer lugar através da Internet. Aktan, et al. (1996) descreveu em seu trabalho a grande importância da experiência prática para os alunos e o ganho de tempo, energia e dinheiro ao se permitir que um único laboratório possa ser mais amplamente utilizado, reduzindo o custo de experimento por aluno e podendo ter a experiência de usar um laboratório físico sem a necessidade de estar presente no laboratório.

Tzafestas, et al. (2006) fizeram uma avaliação comparativa entre os laboratórios virtual e remoto e chegaram à conclusão que laboratórios virtuais, apesar da ausência de presença física, são capazes de prover elementos de aprendizagem adequados aos alunos, particularmente em relação às habilidades mais complexas. Em contrapartida, Balamuralithara \& Woods (2009) afirmaram que os laboratórios remotos são a experiência mais próxima da realidade em contraponto aos laboratórios virtuais que dependem da qualidade de visualização da simulação para atender uma demanda mais realista. Eles também afirmam que laboratórios virtuais não podem fornecer uma "sensação" para as coisas reais. Assim, torna-se imprescindível que os alunos utilizem e executem comandos em ferramentas reais para adquirir habilidades práticas necessárias.

Dentre os trabalhos relacionados que serviram de base teórica para este trabalho, foi observado que a maior parte utiliza robôs que possuem alto custo, tais como os kits robóticos da Lego Mindstorms e o Scorbot ER-IX da Intellitek, (Casini, et al., 2012), (Chaos, et al., 2013) e (Jara, et al., 2011). Apenas DAbreu, et al. (2006) e Mondada, et al. (2009) demonstraram a preocupação em utilizar ferramentas de baixo custo. Após fazerem uma revisão da literatura sobre laboratórios reais, remotos e virtuais, Ma \& Nickerson (2006) chegaram à conclusão que há espaço para a pesquisa que vise a criação de uma mistura entre laboratórios virtuais e remotos, dados os avanços tecnológicos e as pressões de custos sobre as instituições de ensino. Dessa forma, a presente plataforma pretende somar as tecnologias de laboratórios virtual e remoto a fim de ampliar as opções da experimentação prática e proporcionar ao aluno um entendimento mais universal do que foi abordado na teoria e assim expandir seus conhecimentos cognitivos. 
CBIE-LACLO 2015

Anais do XXVI Simpósio Brasileiro de Informática na Educação (SBIE 2015)

\section{Ferramentas e Métodos}

Nesta seção serão explanados como estão sendo desenvolvidos os componentes que fazem parte deste projeto.

\subsection{O Robô Real}

O robô real (Figura 1), cujo protótipo foi baseado no modelo de Souza (2014), possui base circular com diâmetro de $20 \mathrm{~cm}$ e $1 \mathrm{~cm}$ de espessura, duas rodas de 8 " com eixos colineares e um rodízio. O hardware do robô foi equipado com uma placa Arduino Mega 2560, oito sensores omnidirecionais ultrassônicos, uma bússola, um circuito impresso, uma bateria de 5000 mAh e um transceiver, que fará a comunicação remota.

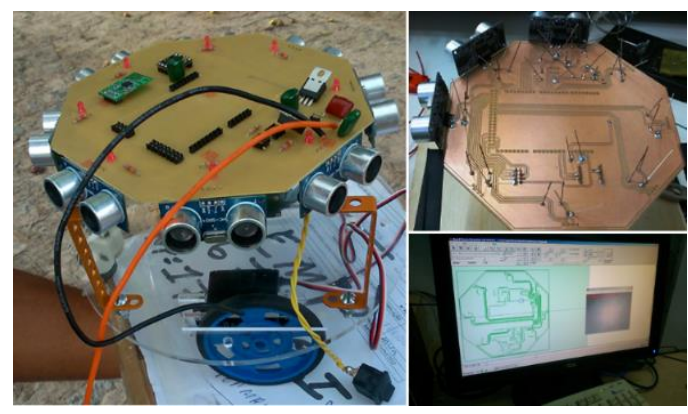

Figura 1. Robô real (em construção) Fonte: Autora

\subsection{O Robô Virtual}

Os softwares simuladores de robôs possibilitam uma diminuição no ônus financeiro gerado pela compra de equipamentos, aumento do espaço físico, contratação de pessoas, dentre outros expedientes que demandam custos elevados na manutenção da infraestrutura de laboratórios físicos (DAbreu, et al., 2006), além de manter os alunos atualizados com as rápidas alterações dos produtos oferecidos no mercado e o avanço tecnológico.

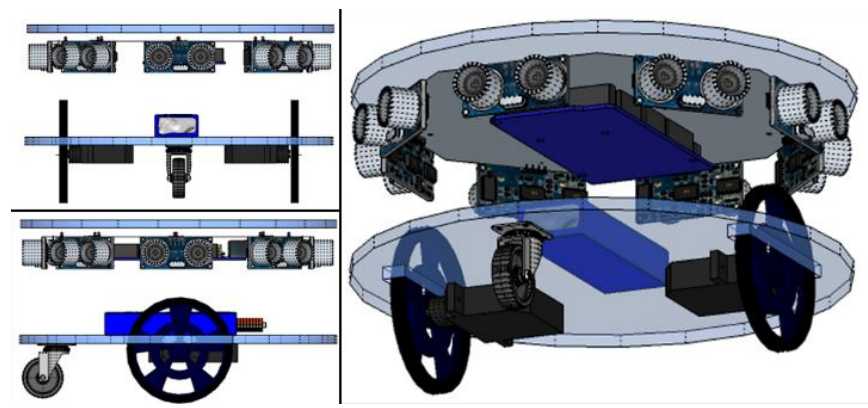

Figura 2. Diferentes ângulos do robô virtual Fonte: Autora

Para a modelagem do presente robô virtual (Figura 2) foi utilizada a versão gratuita do software de modelagem tridimensional (3D), o SketchUp Make 2015. O mesmo possui uma vasta biblioteca online que contém componentes que foram modelados e disponibilizados gratuitamente pela comunidade de usuários denominada $3 D$ Warehouse. Dessa forma, a modelagem de um protótipo complexo é facilitada e agilizada dada a gama de opções. 
Posteriormente o robô virtual foi exportado para um simulador 3D, o USARSim (Simulador de Pesquisa e Salvamento Urbano), que é um simulador independente e multiplataforma (Windows, Linux e MacOS). Carpin et al. (2007) descreve o USARSim como uma ferramenta onde usuários podem manipular e configurar facilmente robôs virtuais, de acordo com sua necessidade. Assim sendo, o sistema de controle de robô escolhido foi o Player que oferece uma interface limpa e simples para controle de sensores e atuadores do robô através da rede IP.

\subsection{A Plataforma}

$\mathrm{Na}$ modalidade de EaD é o aluno quem determina seu ritmo e método de estudo e aprendizagem, de acordo com suas necessidades, e o professor assume um papel secundário orientando o aluno em sua jornada. Dessa forma, a presente plataforma irá maximizar o aproveitamento dos estudos do alunado, estimulando sua autonomia.

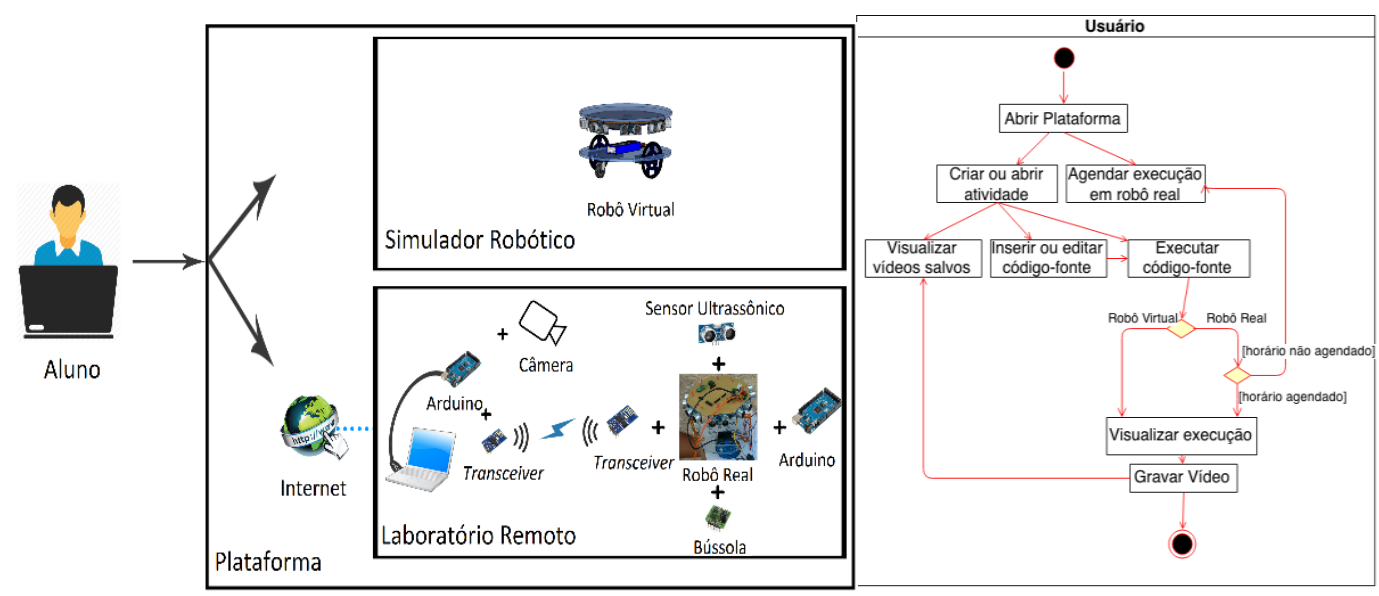

Figura 3 - Arquitetura básica (à esq.) e Diagrama de atividades (à dir.) Fonte: Autora

A plataforma poderá ser acessada em qualquer sistema operacional (Windows, Linux e MacOS), será livre e aberta. Conforme o diagrama de atividades (Figura 3), o aluno poderá criar atividades onde será possível inserir e editar códigos-fonte para controle do robô. A fim de melhorar o entendimento do aluno sobre o funcionamento do robô, os dados captados pelos sensores e atuadores serão facilmente acessados pelo aluno dentro da plataforma. A partir daí o aluno poderá executar o código-fonte e então escolher se deseja trabalhar com o simulador robótico, com o laboratório remoto ou ambos a fim de obter um resultado comparativo entre as diferentes experimentações práticas. Especificamente sobre o laboratório remoto, para fins de otimização de utlização, será necessário a agendamento prévio. O aluno ainda poderá gravar vídeos da execução de sua atividade para uso posterior.

$\mathrm{O}$ acesso ao laboratório remoto consiste no envio do código-fonte através da plataforma conectada à Internet para um servidor web que, por sua vez, transmitirá o código-fonte para um receptor localizado no robô. Após isso, o robô executará os comandos que serão capturados e retornados via streaming à plataforma do aluno.

\section{Considerações Parciais e Trabalhos Futuros}

Frente aos aspectos apresentados, observou-se que existe na EaD a necessidade de uma solução de baixo custo que faça a união de laboratórios remoto e virtual a fim de 
proporcionar aos alunos experiências práticas, significativas e relevantes e, ao mesmo tempo, que estejam on-line, pois, independentemente da modalidade de ensino (presencial e a distância) devem existir coerência onde os graduados de ambos as modalidades possam demonstrar as mesmas capacidades (Balamuralithara \& Woods, 2009). Essa solução pode ser demonstrada no presente trabalho com o desenvolvimento desta plataforma que é de baixo custo, livre, aberta abrindo os horizontes para a melhoria da $\mathrm{EaD}$ nos cursos de engenharias e computação.

Após a conclusão da plataforma, a mesma será disponibilizada gradualmente para o acesso de grupos de alunos com o objetivo de realizar testes e comprovar sua eficiência.

\section{Referências}

ABED - Associação Brasileira de Educação a Distância, 2014. Censo EaD.br: relatório analítico da aprendizagem a distância no Brasil 2013, Curitiba: Ibpex.

Aktan, B., Bohus, C., Crowl, L. \& Shor, M., 1996. Distance learning applied to control engineering laboratories. Education, IEEE Transactions on, Aug, 39(3), pp. 320-326.

Balamuralithara, B. \& Woods, P. C., 2009. Virtual laboratories in engineering education: The simulation lab and remote lab. Computer Applications in Engineering Education, 17(1), pp. 108-118.

Carpin, S. et al., 2007. USARSim: a robot simulator for research and education. Robotics and Automation, 2007 IEEE International Conference on, 10-14 April, pp. 1400-1405.

Casini, M., Garulli, A., Giannitrapani, A. \& Vicino, A., 2012. A remote lab for multirobot experiments with virtual obstacles. s.1., s.n., pp. 354-359.

Chaos, D., Chacón, J., Lopez-Orozco, J. A. \& Dormido, S., 2013. Virtual and Remote Robotic Laboratory Using EJS, MATLAB and LabVIEW. Sensors, 13(2), pp. 2595-2612.

DAbreu, J. V. V., Chella, M. T. \& Ruschel, R. C., 2006. Uso de um robô móvel no experimento de conforto funcional. s.1., s.n., pp. 1-8.

Jara, C. A., Candelas, F. A., Puente, S. T. \& Torres, F., 2011. Hands-on experiences of undergraduate students in Automatics and Robotics using a virtual and remote laboratory. Computers \& Education, 57(4), pp. 2451-2461.

Ma, J. \& Nickerson, J. V., 2006. Hands-on, Simulated, and Remote Laboratories: A Comparative Literature Review. ACM Comput. Surv., \#sep\#.38(3).

Mondada, F. et al., 2009. The e-puck, a $\{R\}$ obot $\{D\}$ esigned for $\{E\}$ ducation in $\{E\}$ ngineering. Portugal, IPCB: Instituto Politécnico de Castelo Branco, pp. 59-65.

Souza, W. G., 2014. Um estudo de casos para auxilio à definição de um modelo de portabilidade na implementação de algoritmos simulados em robôs reais, s.1.: Universidade Federal da Paraíba.

Tzafestas, C., Palaiologou, N. \& Alifragis, M., 2006. Virtual and remote robotic laboratory: comparative experimental evaluation. Education, IEEE Transactions on, Aug, 49(3), pp. 360-369. 